\title{
Dermatological Aspects of a Humanitarian Mission
}

Róbert Késmárszky $^{1^{*}}$, Anna Jakkel ${ }^{2}$ and György Szabó ${ }^{3}$

${ }^{1}$ Department of ENT, Head and Neck Surgery, CH Andrée Rosemon, Cayenne, French Guiana

${ }^{2}$ Family physician, Kecskemét, Hungary

${ }^{3}$ Family physician, Pócsmegyer, Hungary

*Corresponding author: Róbert Késmárszky, Department of ENT, Head and Neck Surgery, CH Andrée Rosemon, Cayenne, French Guiana, Tel: 0620 335 2855; Email: kesmarszky@yahoo.fr

Received date: November 18, 2015; Accepted date: January 12, 2016; Published date: January 18, 2015

Copyright: @ 2015 Késmárszky R, et al. This is an open-access article distributed under the terms of the Creative Commons Attribution License, which permits unrestricted use, distribution, and reproduction in any medium, provided the original author and source are credited.

\begin{abstract}
Background: Patients with dermatological patholgies represent an important population, especially in developing countries. The cosmetological aspects are important.
\end{abstract}

Objective: To determine the incidence and epidemiology of skin diseases during a humanitarian mission.

Methods: 679 patients who presented to our general medical consultations were examined. Patient data was registered to be analyzed retrospectively. The rare and difficult cases were systematically discussed during the consultation. The patient charts were correlated by the corresponding photos.

Results: The ethnic origin of the patients was different. The majority of our patients were younger than 50 years old. The dermatological problems represented a major motivation to consult, namely itching and skin lesions. The incidence was higher when secondary findings and complaints were also considered. Besides scabies, mycosis and tropical pathologies, the problems of scarring represented a major cosmetological demand.

Conclusion: Our work demonstrated a high incidence of dermatological pathologies showing the importance of public health issues, screening and an important need of cosmetological treatments. Due to migration, climatic changes and humanitarian missions, the manifestation and occurrence of the dermatological pathologies may be different. Health care providers need a thorough knowledge of community acquired and tropical pathologies.

Keywords: Humanitarian mission, Public health, Skin, Cosmetology

\section{Introduction}

The dermatological problems are frequent in the Western societies, representing up to $12.4 \%$ of family medicine visits and an important economic burden, especially when lost work days are considered $[1,2]$.

The variety of available cosmetological treatments is important.

In developing and tropical countries the incidence may be higher while access to dermatological diagnostic and therapeutic facilities is reduced or missing, cosmetological treatments and surgery are available only for a small segment of the society. In these countries up to $59 \%$ of the patients may have dermatological problems with a value even higher when thorough examination can be achieved by dermatology specialists [3]. The associated mortality in these areas may be as high as of meningitis, hepatitis B or rheumatic heart disease [4].

The authors report about a population that had no former dermatological care in a developing country.

Their study was affected during a humanitarian mission in Uganda during late 2013.

They report the incidence, epidemiology and presentation of these pathologies.
The influencing factors like climatic and social differences were considered.

\section{Methods}

The study was ethically approved and conducted on patients requesting medical care during a humanitarian mission organized by the African-Hungarian Union in 2013.

\section{Construction of the team}

The medical team was composed of 2 family doctors, one of them specialized in infectology as well and 1 head and neck surgeon.

Former experience in humanitarian work, training in tropical diseases, knowledge of at least one foreign language used in the area, valid vaccinations, appropriate physical and psychological status were the requirements to be selected.

They were accompanied by a coordinator whose duty was the organization of the consultations, travel, security and contact with the local authorities. Local public health doctors, general practitioners and nurses were involved, their cooperation considered to be important during follow-up as well. 


\section{Examined population}

The 679 patients were living in the Hoima area, Uganda by the lake Albert. An ethnic heterogeneity was observed with the presence of refugees from conflict areas.

All of the presenting patients were examined. When English was not spoken by them, local helpers translated.

The age, sex and medical history were systematically taken and regardless of the presenting pathologies, the skin was examined. All of the difficult and rare cases were discussed. The photographic documentation was systematic.

The obtained data, findings, diagnosis and recommended treatments were noted on medical charts to be analyzed at the end of the mission with a second control using the photographic images.

\section{Results}

Due to adapted translation when necessary, there were no problems in communication. The limited access to electricity, drinking water, canalization and health care, cohabitation of several generations in crowded households were common in the area representing important epidemiological factors together with the tropical climate and pathogens [5]. The known and declared HIV infections were present in 24 cases $(3.53 \%)$, lower than the national average but testing was not available during the consultations [6]. Alcoholism and smoking were not present, only 1 smoking patient was detected. The community acquired dermatological diseases, mostly scabies was more frequent amongst the refuges coming from the neighboring crisis areas $[7,8]$. Due to the poverty many people had no shoes, representing a possible way of being infected by worms (GNI per capita: 440 USD) [5,9-11]. Altogether, 679 patients were examined, representing 404 females (mean age 33.29 years) and 275 males (mean age 20.34 years) as shown by decades [Figure 1]. The life expectancy was 58.7 years [5]. The young mean age of our patients may explain the low incidence of skin tumors, only one lesion responding to the criteria of melanoma was seen $[12,13]$. None of them had previous access to dermatological care. Dermatological problems, different masses /dominated by thyroid nodules, hernias, salivary tumors, pathologies of the lymph nodes and others/, abdominal pain and musculoskeletal problems represented the most frequent motivations to consult [Table 1]. Without those of the genital parts and the skin of the external ear canal, dermatological cases represented $12.7 \%$ (86 patients) of the main complaints, 56 $(8.3 \%)$ of them by skin related itching, mostly due to scabies with or without secondary bacterial infection and other skin lesions in 30 cases (4.4\%). Their overall incidence was up to $18.2 \%$ (124 patients) when secondary complaints and findings were considered. In several cases, an association of multiple skin pathologies was observed. Scabies was present in 76 cases $(11.2 \%)$, usually several members of the same family were included. The troubles of scarring, hypertrophic scars and keloid touched 29 (4.27\%) of all patients, 24 (3.53\%) looking for surgical solutions, regardless of the localization and the causes, namely $17(2.5 \%)$ trauma or disease related, $8(1.17 \%)$ due to traditional healing methods and only $4(0.6 \%)$ as complication of former surgery. Mycosis was diagnosed in 37 cases (5.4\%). In 17 patients $(2.5 \%)$ allergy, larva migrans, trauma, burn, varicella, viral papilloma, leprosy, leischmania, tumor and trophic disorders were detected [Table 2].

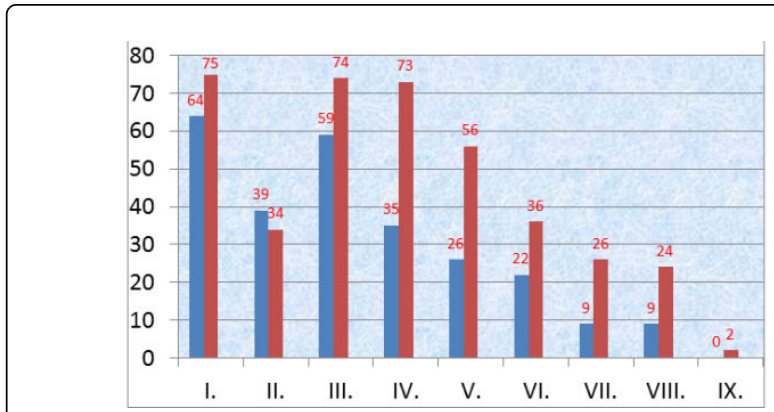

Figure 1: Age and sex distribution by decades.

Males: blue; Females: red; In arabic: years; In roman: decades

\begin{tabular}{|c|c|}
\hline Masses & $91(13.4 \%)$ \\
\hline Dermatological problems & $116(12.7 \%)$ \\
\hline Abdominal pain & $78(11.4 \%)$ \\
\hline Musculosceletal pain & $62(9.1 \%)$ \\
\hline Cough & $49(7.2 \%)$ \\
\hline Headache & $40(5.8 \%)$ \\
\hline Genital problems & $38(5.5 \%)$ \\
\hline Rhinological problems & $36(5.3 \%)$ \\
\hline
\end{tabular}

Table 1: Distribution of the most important main complaints.

\begin{tabular}{|c|c|}
\hline Scabies & $76(11.2 \%)$ \\
\hline Mycosis & $37(5.4 \%)$ \\
\hline Scarring disorders & $29(4.27 \%)$ \\
\hline Others & $17(2.5 \%)$ \\
\hline
\end{tabular}

Table 2: Distribution of the most important skin problems.

\section{Discussion}

The efficacy of a humanitarian mission is based on a careful selection of the participants and their teamwork. A good cooperation with local colleagues and authorities must be organized to achieve an optimal performance and a better follow-up of the patients. Due to linguistic and cultural differences the role of translators is important [7]. To make correct diagnosis, knowledge of the locally occurring pathologies is a must; it may protect the team members from infections as well. The communication amongst the participants is necessary when seeing rare and difficult cases. The diagnosis of skin manifestations caused by tropical and tropically occurring diseases like leprosy, larva migrans, tuberculosis, AIDS, Loa loa, leischmania, yaws and others is challenging. Mycosis and tumors may have unusual forms. Their incidence may be very high due to factors related to the pathogens, climate, migration and social reasons. In the recent study, even without the secondary findings or including the affections of the genital parts and the skin of the external ear canal they represented the second most important group motivating a consultation. As there was no trained dermatology specialist in the team, real incidence must 
Citation: Késmárszky R, Jakkel A, Szabó G (2016) Dermatological Aspects of a Humanitarian Mission. J Allergy Ther 7: 228. doi: 10.4172/2155-6121.1000228

Page 3 of 3

have been higher due to a more effective detection of the corresponding lesions. This way even without knowing the exact incidence, pathologies of the skin may be considered as the most frequent ones. The mortality associated to skin diseases and their incidence in developing countries is higher, trained dermatologists are needed [4]. Despite of the lack of therapeutic means the demand for cosmetological treatments is also important, a higher percentage of the involved patients seeks a solution. The incidence and manifestations of the diseases may differ from one region to another due to climatic, environmental and geopolitical reasons [14]. Due to migration and tourism these pathologies must be considered in Western countries. According to the data of Eurostat at the time of the mission, before the recent elevation in migration 7.5 million tourists visited the main SubSaharan destinations per year and there were more than 700,000 demands of citizenships in Europe from non-European countries [15]. When availability of the public facilities does not correspond with the demand a cohabitation facilitated elevation in the incidence of community acquired pathologies like scabies can be observed [14]. This means that without improving the public facilities and organizing educational campaigns the incidence cannot be reduced significantly even if a better access to health care could be provided.

\section{Acknowledgement}

The authors are grateful for the help of the African-Hungarian Union, the Hungarian Trade Commercial and Cultural Center in Kampala, Virág Kiss, Doctor Tibaijuka Hannington, all of the patients and nurses who helped their job.

\section{References}

1. Verhoeven EW, Kraaimaat FW, van Weel C, van de Kerkhof PC, Duller P, et al. (2008) Skin diseases in family medicine: prevalence and health care use. Ann Fam Med 6: 349-354.
2. Dehkharghani S, Bible J, Chen JG, Feldman SR, Fleischer AB Jr (2003) The economic burden of skin disease in the United States. J Am Acad Dermatol 48: 592-599.

3. Figueroa JI, Fuller LC, Abraha A, Hay RJ (1998) Dermatology in southwestern Ethiopia: rationale for a community approach. Int J Dermatol 37: 752-758.

4. Hay R, Bendeck SE, Chen S, Estrada R, Haddix A et al. (2006) Disease Control Priorities in Developing Countries. Chapter 37 Skin Diseases. 2nd edition. Washington (DC): World Bank.

5. http://www.unicef.org/infobycountry/uganda_statistics.html

6. Muula AS (2010) HIV prevalence and associated behavioral factors in Lesotho, Kenya, Malawi, and Uganda. Croat Med J 51: 271-273.

7. McCaw BR, DeLay P (1985) Demographics and disease prevalence of two new refugee groups in San Francisco. The Ethiopian and Afghan refugees. West J Med 143: 271-275.

8. Hodson EM, Springthorpe BJ (1976) Medical problems in refugee children evacuated from South Vietnam. Med J Aust 2: 747-749.

9. Johnson KE, Guillet N, Murphy L, Horton SE, Todd AT (2015) "If Only We Could Have Them Walk a Mile in Their Shoes": A Community-Based Poverty Simulation Exercise for Baccalaureate Nursing Students. J Nurs Educ 54: S116-119.

10. Jiraanankul V, Aphijirawat W, Mungthin M, Khositnithikul R, Rangsin R, et al. (2011) Incidence and risk factors of hookworm infection in a rural community of central Thailand. Am J Trop Med Hyg 84: 594-598.

11. Heukelbach J, Jackson A, Ariza L, Feldmeier H (2008) Prevalence and risk factors of hookworm-related cutaneous larva migrans in a rural community in Brazil. Ann Trop Med Parasitol 102: 53-61.

12. Erdei E, Torres SM (2010) A new understanding in the epidemiology of melanoma. Expert Rev Anticancer Ther 10: 1811-1823.

13. Rees JR, Zens MS, Gui J, Celaya MO, Riddle BL, et al. (2014) Non melanoma skin cancer and subsequent cancer risk. PLoS One 9: e99674.

14. http://apps.who.int/iris/bitstream/10665/69229/1/ WHO_FCH_CAH_05.12_eng.pdf

15. http://ec.europa.eu/eurostat/statistics-explained/index.php/ Migration_and_migrant_population_statistics 